\title{
Effect of Process Parameters on Density and Mechanical Behaviour of a Selective Laser Melted 17-4PH Stainless Steel Alloy
}

\section{Liang Huang}

Xi'an Technological University

Yan Cao ( $\sim$ caoyan@xatu.edu.cn )

Xi'an Technological University

\section{Gaohong Li}

Xi'an Technological University

Yao Li

Xi'an Technological University

Yunpeng Dang

Xi'an Technological University

\section{Yuanfei Wang}

Xi an KunLun Industry (Group) Company with Limited Liability

\section{Research Article}

Keywords: Selective laser melting, 17-4PH pre-alloy powder, Spheroidization, Process parameters, Temperature transfer gradient, Mechanical, behaviour

Posted Date: December 10th, 2020

DOl: https://doi.org/10.21203/rs.3.rs-121511/v1

License: (c) (i) This work is licensed under a Creative Commons Attribution 4.0 International License. Read Full License

Version of Record: A version of this preprint was published at Open Physics on January 1st, 2022. See the published version at https://doi.org/10.1515/phys-2022-0008. 


\title{
Effect of Process Parameters on Density and Mechanical Behaviour of a Selective Laser Melted 17-4PH Stainless Steel Alloy
}

\author{
Liang Huang ${ }^{\mathrm{a}}$, Yan $\mathrm{Cao}^{\mathrm{a}, *}$, Gaohong $\mathrm{Li}^{\mathrm{b}}$, Yao Li ${ }^{\mathrm{a}}$, YunPeng Dang ${ }^{\mathrm{a}}$, Yuanfei Wang ${ }^{\mathrm{c}}$ \\ a Mechatronic Engineering, Xi'an Technological University, Xi'an, China \\ 'Materials and Chemical Engineering, Xi'an Technological University, Xi'an 710021, China \\ c Tool Structure Manufacturing, Xi'an KunLun Industry (Group) Company with Limited Liability, Xi'an, China \\ * Yan Cao: caoyan@xatu.edu.cn; Tel.: 029-86173054.
}

\begin{abstract}
17-4 PH stainless steel alloy has been widely used in the field of defense industry such as weapon equipment, aerospace, nuclear energy and so on because of its high strength, high toughness, high temperature resistance and corrosion resistance. In order to meet the flexible manufacturing requirements of multi-variety small batch complex structure products with lower cost and higher efficiency, Selective laser melted 17-4PH stainless steel alloy has become the focus of research in the field of rapid alloy manufacturing in recent years. This paper studied the density characteristics and the distribution characteristics of holes and spheroidization phenomena of 17-4 PH pre-alloyed powder subjected to multidimensional temperature conduction under selective laser melting, and the mechanism of defect generation under temperature conduction is proposed. Finally, the optimal selection of the combination of different process parameters waere carried out by orthogonal test, and it was found that the comprehensive mechanical behaviour of the 17-4 PH stainless steel alloy after formed exceeded the ASTM A564 standard (the yield strength is $1132 \mathrm{MPa}$, the tensile strength is $1323 \mathrm{MPa}$, the elongation is $16.6 \%$ ).
\end{abstract}

Keywords Selective laser melting $17-4 \mathrm{PH}$ pre-alloy powder-Spheroidization·Process parameters-Temperature transfer gradient $\cdot$ Mechanical behaviour

\section{Introduction}

As an important member of additive manufacturing (AM), selective laser melting (SLM) has been in the frontier of advanced manufacturing after nearly 30 years of rapid progress. At present, domestic and foreign industrial fields have gradually begun to expand SLM technology for parts processing and manufacturing, including aerospace, medicine, common mold manufacturing and so on. Meanwhile, $[1,2]$ in the research and development of forming equipment, technology and materials, SLM technology has achieved a lot of results. For example, $[3,4]$ in the actual production process, the application of this technology to the cemented carbide products with complex-shaped structure can avoid the problems of long period and high cost in traditional cutting methods, and the flexible manufacturing with small batch and multi-variety characteristics can be realized for all kinds of products with complex-shaped structure. As a kind of gun steel materials, 17-4PH, [5] due to its excellent strength, corrosion resistance and toughness, has been widely used in aircraft guns, naval guns and other military hardware and show the excellent mechanical properties, when its working temperature is not more than $500^{\circ} \mathrm{C}$. At present, the main traditional processing methods for $17-4 \mathrm{PH}$ materials include casting and forging. However, in recent years, in order to adapt to the changing flexible demand of the market, the rapid and precise manufacturing of multi-variety and small-batch complex structure products has gradually become its future development direction, and also challenges the above-mentioned traditional mass quantitative manufacturing modes. Consequently, how to achieve high-efficiency and low-cost flexible manufacturing under the premise of ensuring product quality accuracy and efficiency is the technical bottleneck to be solved and concerned by gun steel manufacturing enterprises in recent years as well. Along with the development of SLM rapid prototyping technology in recent years, more new alloy materials are developed successfully, and the selective laser melting gun steel materials becomes possible.

Due to the selective laser melting technology of this material was introduced recently, so related researches on SLM forming of 17-4PH alloy are relatively few. Such as: [6] Spierings and [7] Gu explored the mechanical properties of 17$4 \mathrm{PH}$ powder in SLM forming process with different process parameters, and summarized some laws. [8] Murr investigated the changes of martensite and austenite of 17-4PH formed parts by changing different protective atmosphere in the forming environment. Based on above studies, [9] Dai studied the density and dimensional accuracy of SLM molded 17-4PH stainless steel with different process parameters. [10] The microstructure and macroscopic mechanical properties of 17 4PH stainless steel formed parts treated with heat treatment and without heat treatment were compared by Professor $\mathrm{Gu}$ and his team, it is considered that heat treatment is helpful to the modification of tissue.

Based on above analyses, it can be seen that although the microstructure and mechanical behaviour of 17-4 PH alloy 
formed under different process parameters were studied, the mechanism of density of 17-4 PH alloy formed by different process parameter was less studied. Therefore, this paper selected 17-4 PH stainless steel pre-alloy powder material to carry on SLM researches on EOS M290 forming equipment by exploring 17-4 PH stainless steel powder material rheological characteristic, and combining with different process parameters. The effects of the process parameters on the microstructure defects were investigated, and the optimum mechanical properties of the formed parts were obtained by orthogonal test under the condition of the microstructure guarantee. Thus, a theoretical foundation for the preparation of 17-4 PH stainless steel parts with high density and high performance SLM forming was laid.

\section{Experimental}

\subsection{Selection of 17-4PH pre-alloy powder}

The 17-4 PH pre-alloyed powder components selected in this paper meet the ASTM A564 standard. For selective laser melting technology, the structure of pre-alloyed powder affects the quality of forming parts to a certain extent. If the pre-alloyed powder is mostly non-spherical, this will lead to the material after heating, powder particles in the process of self-adhesion, the unadhesive part due to the hot melt and form a bottleneck structure and gradually spheroidization, and then will gradually melt, and in the process of laser scanning, the stress on the split body of the material will be dispersed in the direction of horizontal and forming direction, and the direct effect of this stress dispersion on the formed part is to warp the formed part. In contrast, the spherical powder material only experiences the process of melting and remelting cooling of the powder during laser irradiation, so the stress produced by laser scanning is rarely dispersed in the horizontal direction, which made the shrinkage volume of the sample is less during the forming process, thus avoiding the warping deformation. In this paper, the sophericity of 17-4 PH stainless steel pre-alloy powder were measured and analyzed by BT-1600 image particle distributor analysis system, and the distribution of sophericity interval of 17-4 PH stainless steel powder were shown in Table 1 and Fig. 1-2 below. As shown above, the pre-alloyed powder was found to be dense and spherical in general, and the dense and smooth powder surface guaranteed good flow characteristics, which were beneficial for the powder feeding process.

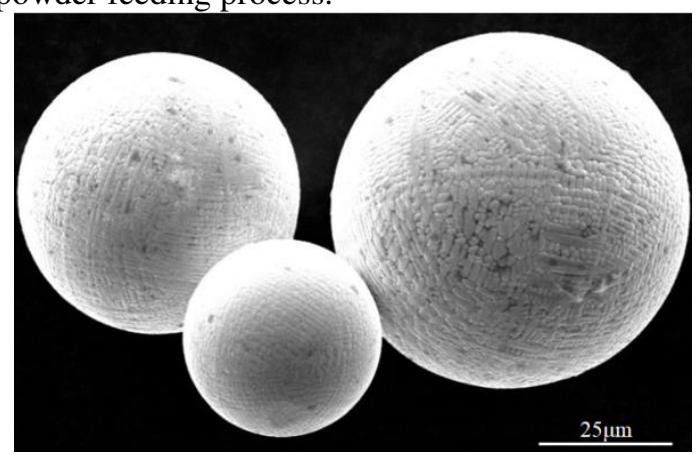

Fig.1 The microstructure of 17-4PH pre-alloy powder

Table 1 The sophericity distribution of
17-4PH pre-alloy powder

\begin{tabular}{cccc}
\hline $\begin{array}{c}\text { Maximum } \\
\text { sophericity/ } \boldsymbol{\mu m}\end{array}$ & $\begin{array}{c}\text { Minimum } \\
\text { sophericity/ } \boldsymbol{\mu m}\end{array}$ & $\begin{array}{c}\text { Average } \\
\text { sophericity/ } \boldsymbol{\mu m}\end{array}$ & $\begin{array}{c}\text { Span } \\
/ \boldsymbol{\mu m}\end{array}$ \\
\hline 0.999 & 0.558 & 0.873 & 0.161 \\
\hline
\end{tabular}

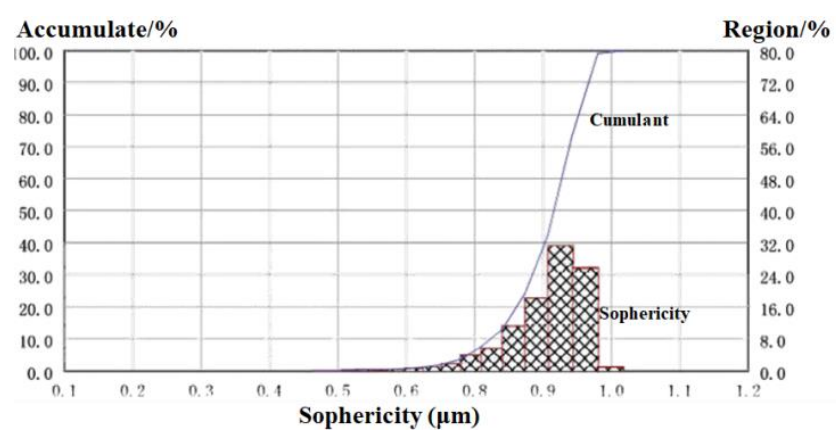

Fig.2 The sophericity distribution of 17-4PH pre-alloy powder

Distribution of the particle size of the pre-alloyed powder in a reasonable range will make the powder show good fluidity in the forming process. Correspondingly, the quality of powder laying depends on the fluidity of the material. Good fluidity can make the SLM-formed parts of the material have high quality. In this paper, the pre-alloyed powder particle size distribution curve was measured by a Mastersizer laserdiffraction diameter tester (model: ms3000) (as shown in Fig. 3 ). The pre-alloyed powder particle size was in the range of 20-60 um, and the median particle diameter was 55 um. Therefore, the selected powder presented a sufficient particle size.

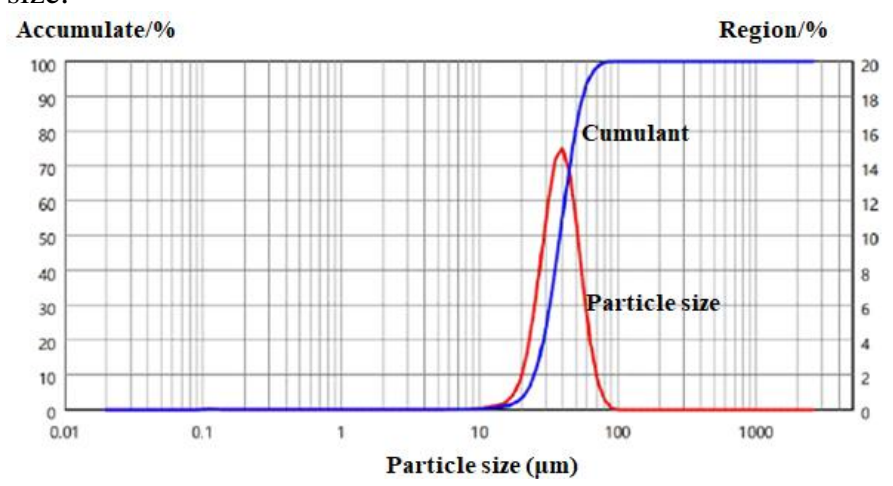

Fig.3 The particle size distribution curve of 17-4PH pre-alloy powder

For the characterization of the printability of the selected pre-alloyed powder by rheological characteristic, the material viscosity test (Prepare $50 \mathrm{ml}$ of deionized water in a beaker then adding $8 \mathrm{~g}$ pre-alloy powder to deionized water and stir 2 min with agitator to produce mixed suspension; Then, $0.104 \mathrm{~g}$ hydroxypropyl methyl cellulose (HPMC,4000 viscosity) was added for mixing and stirring for $1 \mathrm{~h}$, and $0.136 \mathrm{~g}$ polyethylene imine (PEI, $\left.M_{\mathrm{w}}=1800\right)$ was used for bridging flocculation and continued stirring until the mixed solution was uniform, so the $17-4 \mathrm{PH}$ pre-alloy powder suspension mixed samples were obtained for rheological properties measurement; Finally, at room temperature, the viscosity of materials at different time was obtained by changing the shear rate by using rheometer (model: Anton Paar MCR301), the 
results as shown in Fig. 4) was used to characterize the printability of the 17-4 PH pre-alloyed powder. It can be seen that the viscosity of the material will gradually decrease with the increase of the applied shear rate, which reflects the shear viscosity reduction characteristics of the materia, during this process, 17-4 PH pre-alloy powder materials show obvious pseudoplastic flow. In the study of pseudoplastic flow materials, there are the following research formulas:

$$
\eta=K \gamma^{n-1}
$$

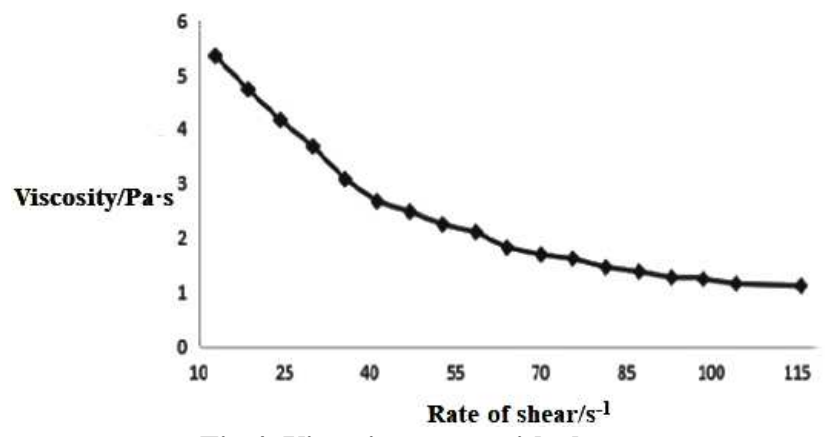

Fig.4 Viscosity curve with shear rate

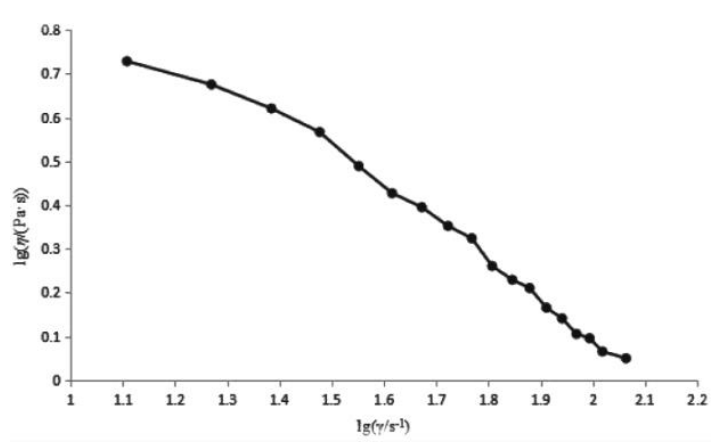

Fig.5 $\lg \eta$ - $\lg \gamma$ relation curve

In which, $\eta$ represents the viscosity of the material, $\gamma$ represents the size of the shear rate during the experiment, $K$ represents the constant coefficient, $n$ is the fluidity index of the material, $n<1$. During the study of the forming properties of metal powder materials, the fluidity index of the material $n$ reflect the degree of the change of the viscosity value of the sample with the shear rate, which is a very critical performance index. It is generally believed that the larger the fluidity index, the less sensitive the viscosity value of the material is to the change of shear rate and the slower the change rate, and the deformation of this material generally has good stability, but the metal powder material in this case does not show sufficient shear thinning behavior. [11] On the basis of this situation, it is proposed that under the premise of $n>0.2$, the value of $n$ should be as small as possible. This value is because, with the decrease of the $n$ value, the smaller the $n$, the faster the viscosity of the powder material changes with the shear rate. Selective laser melting is carried out rapidly at a certain temperature, so this characteristic of the material is beneficial to the molding of the material. According to the above formula 1, a double logarithmic diagram of the relationship between sample viscosity and shear rate, that is, $\lg \eta-\lg \gamma$, as shown in Fig .5. It can be seen that the logarithmic line slope of the material viscosity and shear rate in Fig. 6, the value of the epidemic index $n$ of the sample can be calculated, that is $n=0.2898$, [12] so the material has good selective laser melting forming property.

\subsection{Selection of 17-4PH SLM-formed parts metallographic equipment}

In this experiment, the surface of the sample were polished by using 100\#, 240\#, and 400\# coarse sand in turn, and then polished on the fine sand paper of 800\#, 1000\#, 1500\#, 2000\#, and 3000\# in turn, and then used the PG-2D polishing machine (which diameter of the polishing wheel is $230 \mathrm{~mm}$, the maximum idle speed is $900 \mathrm{r} / \mathrm{min}$ on the left and $700 \mathrm{r} / \mathrm{min}$ on the right), until there is no obvious scratch on the surface of the sample. After that, the corrosion treatment before the metallographic experiment of the sample is carried out, so that the internal structure of the sample can be observed under the microscope. The corrosion solution used in this experiment is a mixture of $15 \mathrm{~mL}$ glycerin, $10 \mathrm{~mL}$ hydrochloric acid and $5 \mathrm{~mL}$ nitric acid. The corrosion reaction of the sample is carried out in the corrosion solution or dipped in some corrosion solution for a period of time. The corrosion time can be simply adjusted according to the shape and size of the sample. Finally, the Nicon300 optical microscope, which equipped with lenses ranging from 50x to 1000x for easy observation and analysis of samples from different magnification angles.

\subsection{Selection of the density measurement method for 17 - 4PH SLM-formed parts}

In this experiment, Archimedes method is used to measure the density of samples. In order to ensure the accuracy of the experiment, the sample to be tested should be cleaned by ultrasonic cleaner before the experiment (the solution of the sample to be cleaned is a mixture of acetone and water, and the sample needs to be dried after cleaning), so as to avoid the interference of the residual stains on the surface of the sample to the experimental results. When the measurement begins, use an electronic balance to weigh the mass of the sample to be measured $M_{1}$, then prepare a beaker containing enough distilled water, and use an electronic balance to weigh its mass $M_{2}$, then tie the sample to the beaker slowly, it should be noted that the sample can not touch the cup wall and bottom of the beaker during the measurement process, otherwise it will affect the experimental results, after the balance is stable, record the reading $M_{3}$ at this time. Finally, the density of the sample can be obtained by using formula (2) and formula (3).

$$
\begin{gathered}
\rho_{0}=\frac{M_{1} \rho_{1}}{M_{3}-M_{2}} \\
A=\frac{\rho_{0}}{\rho_{2}}
\end{gathered}
$$

In which, $\rho_{1}$ represents the density of water; $\rho_{0}$ represents the actual density of the sample; $\rho_{2}$ represents the theoretical density of the sample; $A$ represents density.

\subsection{Selection of the mechanical behaviour analysis equipment for 17-4PH SLM-formed parts}

Tensile test mainly included tensile strength test and yield strength test of the selective laser melted parts. The finished stretch piece must be polished to a surface roughness $R a$ of 
$1.6 \mu \mathrm{m}$ and be used in tensile tests. Before testing, the length of the sample is measured firstly, and the test parameters are set when stretching: pre-loading $50 \mathrm{KN}$, and tensile rate $5 \mathrm{~mm} / \mathrm{min}$. After the sample is pulled, the data system could provide the corresponding data based on the pre-experiment setting, including the tensile strength $\left(\sigma_{\mathrm{B}}\right)$ and yield strength of the sample $\left(\sigma_{\mathrm{s}}\right)$. Meanwhile, according to the national standard GB/T 228.1-2010-tensile test of metal materials part 1: room temperature test methods, the tensile samples are shown in Fig.6.

Unit: mm
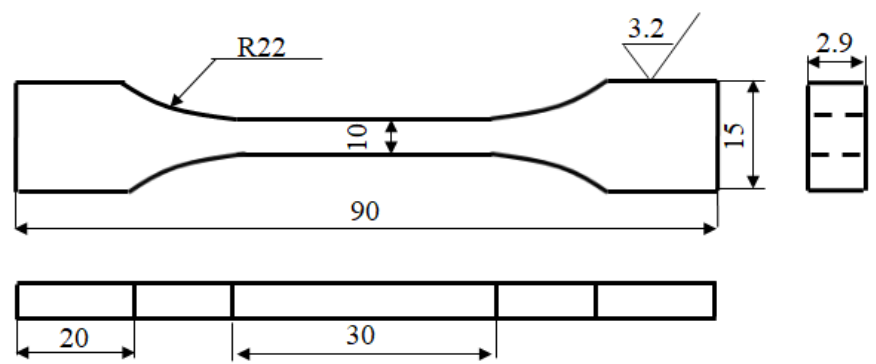

Fig. 6 Schematic diagram of the tensile samples

\section{Results}

3.1 Analysis of density of 17-4PH SLM-formed parts under different process parameters

Due to the principle of selective laser melting is to melt the pre-alloyed powder by high energy laser beam, and the rapid cooling solidification occurs after the laser beam is removed. Therefore, the forming density and quality of the material are mainly restricted by the laser energy of the laser source of the equipment in each formed position and caused by the longitudinal/transverse heat transfer during the sequential sintering between adjacent molten pools/ molten channels. In this paper, through a large number of forming tests, a set of parameters are selected within the range of process parameters that can be formed (scanning speed: $15-45 \mathrm{~mm} / \mathrm{min}$; laser power: $160-220 \mathrm{~W}$; scanning spacing: $9-13 \mu \mathrm{m}$ ), so the forming density under the action of each process parameter is studied by using the control variable method, and the distribution mechanism of material density defect with temperature gradient conduction property is established.

\subsubsection{Scanning speed}

The laser scanning speed is used to reflect the fixed laser energy time of the pre-alloyed powder in the unit forming area, and also reflects the pause time between the two adjacent laser injection points. Its mainly by changing the sintering time in the unit forming area to change the thermal energy of the prealloyed powder and acting on the solid-solution aging of the material. This part taken a certain process parameter as an example (scanning speed: $15-45 \mathrm{~mm} / \mathrm{min}$; laser power: $200 \mathrm{~W}$; scanning spacing: $11 \mu \mathrm{m}$ ), and the metallographic phase diagram shown in Fig.7 is obtained by dividing the scanning speed into four stages.

It can be seen from Fig. 7 that when the laser power and scanning spacing are fixed as medium parameters, and the scanning speed is higher, so the solidification time of the prealloyed powder in the unit sintering area is shorter because of the short heating time, and the width size of the molten pools/molten channels are smaller (as shown in Fig. 7(a)). Meanwhile, with the decrease of scanning speed, the heat of the pre-alloyed powder in the unit sintering area increases gradually, as a result, Fig. $7 \mathrm{~b}$ has a wider-size molten pools structure than Fig. 7a, and Fig. 7d has a wider-size molten channels structure than Fig. 7c, and the lap quality of the whole material between adjacent molten pools/molten channels decreases gradually, which is mainly reflected in Fig. $7 \mathrm{~d}$ as the inconsistency of the width size of adjacent molten channels.
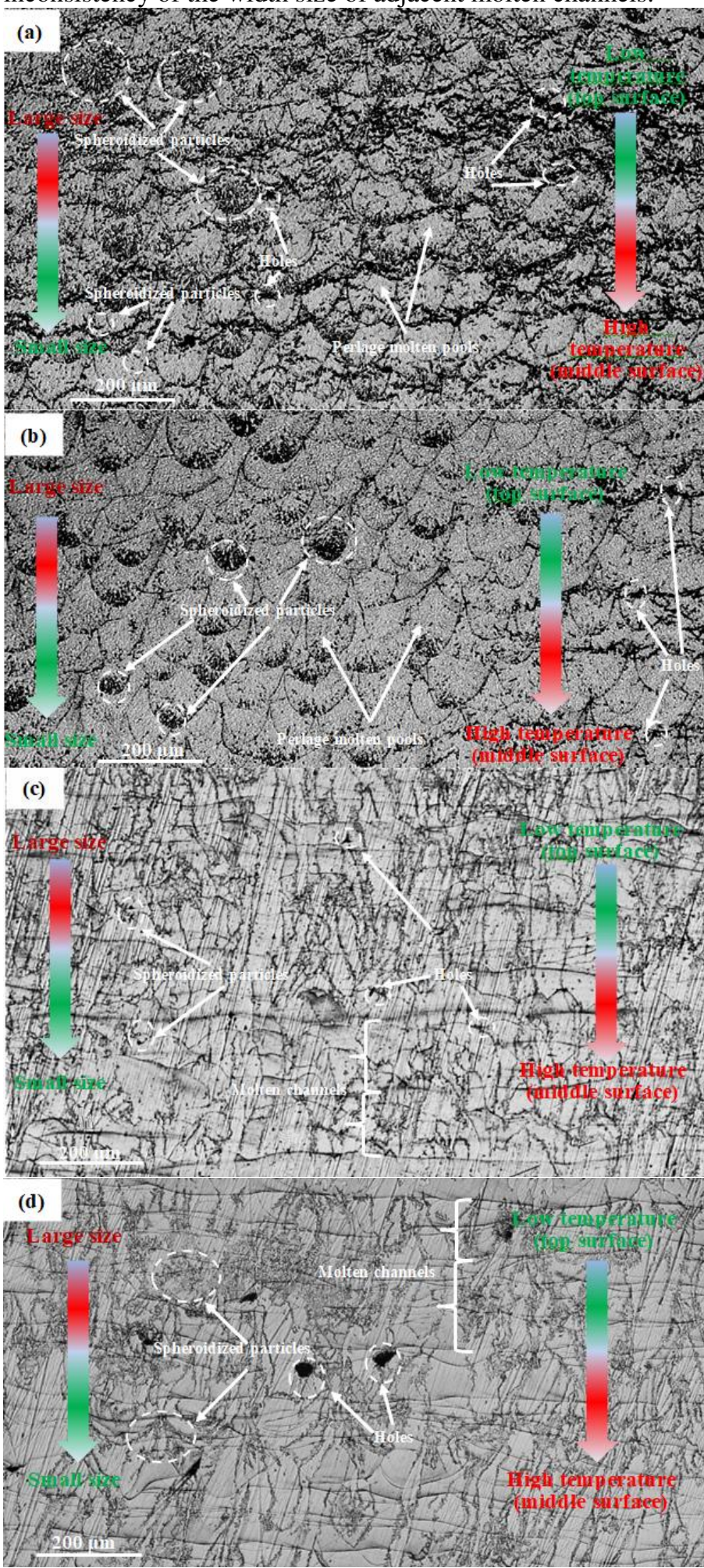
(a) $45 \mathrm{~mm} / \mathrm{min}$; (b) $35 \mathrm{~mm} / \mathrm{min}$; (c) $25 \mathrm{~mm} / \mathrm{min}$; (d) $15 \mathrm{~mm} / \mathrm{min}$; Fig.7 Metallographic phase of samples under different scanning speed

Subsequently, [13] spheroidized particles with small ellipsoidal structure and [14] irregular holes with large size were found in each molten pools/ molten channels in Fig. 7 and showed similar distribution. The reason is that when the scanning speed is high (as shown in Fig. 7(a)), on the one hand, the heat produced by the laser source in the unit sintering area is less, so that the pre-alloyed powder in each scanning path can not be fully sintered and a part of the holes are formed by the powder stacking; On the other hand, considering the short time of solid solution aging, and the liquid vapor produced by the material during melting and the external gas absorbed by the oxide during solidification can not be eliminated in time due to the high solidification rate in the molten pools/ molten channels, thus forming another part of the holes, meanwhile, [15] considering that the bubble solubility increases with the increase of laser energy density during selective laser melting proposed by Xiao et al and the sufficient of powder sintering gradually increased, the holes decreases with the decrease of scanning speed, and at a scanning speed of $25 \mathrm{~mm} / \mathrm{min}$ to achieve the best (as shown in Fig. 7(b-c)). However, when the scanning speed is reduced to a certain extent, because the laser energy in the molten pools/molten channels is too high, the scanning width of the corresponding molten pools/molten channels will become larger and the formed part of the previous layer will be secondary melted and heat transferred, as a result, the gas that can not be discharged in time in the previous layer will be heated and expanded, and finally the hole size becomes larger(as shown in Fig. 7(d)). For spheroidization, the formation mechanism is similar to that of holes, which is restricted by temperature transfer. First of all, when the scanning speed is too high in the forming process (as shown in Fig. 7(a)), the pre-alloyed powder in the forming layer can not be completely melted, in addition, when the molten liquid metal flows under the coupling of its surface tension and solidification gradient, and the liquid metal meets the unmelted solid powder particles, the liquid metal will be coated in the outer layer of its surface, and when the laser movement occurs rapid cooling to form spheroidized particles, due to more spheroidized particles are produced at this time, so larger size spheroidized particles will be formed by annexation (as shown in Fig. 7(a)); In the process of increasing the scanning speed gradually (as shown in Fig. 7(b-c)), the prealloyed powder absorbs more energy, so it transforms more powder into molten metal, thus reducing the spheroidization. However, when the scanning speed is reduced to a certain extent, the excessive laser energy will accelerate the gasification rate of liquid metal, and the smaller spheroidized particles will be attached to the forming layer by vaporization rising and solidification (as shown in Fig. 7(d)). In addition, considering that the temperature gradient direction in the molten pools are longitudinal along the forming direction, while the temperature gradient direction in the molten channels are the radial direction of sintering in turn, this will lead to spheroidization and holes in each molten pool mainly concentrated at the bottom of the lower temperature, while spheroidization and holes in the molten channel are mainly concentrated on both sides of the boundary of the lower temperature, and generally all decrease along the temperature gradient, and the corresponding temperature gradient determines the size and quantity of spheroidization and holes, so the distribution of spheroidization and hole along the temperature gradient can be observed by Fig. 7 .

\subsubsection{Laser power}

Laser power is the key process parameter which directly affects the density and quality of SLM-formed parts. Its size directly determines the heat energy of the unit forming area of the prealloyed powder in unit time, and is finally reflected in the solid-solution aging process of the material. Through the analysis of the above scanning speed, it can be seen that the scanning speed is mainly by changing the sintering time in the unit forming area to change the thermal energy of the prealloyed powder and acting on the solid-solution aging of the material. Therefore, the influence mechanism of these two parameters on the density of materials is consistent. Based on above forming process parameters range and the best scanning speed parameters (scanning speed: $25 \mathrm{~mm} / \mathrm{min}$; laser power: 160-220 W; scanning spacing: $11 \mu \mathrm{m})$, and the metallographic phase diagram shown in Fig. 8 is obtained by dividing the laser power into four stages.

It can be seen from Fig. 8 that when the scanning speed and scanning spacing are fixed as medium parameters, and the laser power is lower (as shown in Fig. 8(a)), so all the pre-alloyed powders on the forming layer can not absorb enough heat so that most of the powder inside the forming layer can not be fully melted, and the temperature gradient in the forming layer is small, so that in the forming layer shows the phenomenon that the radial molten channel width is small and the adjacent channel spacing is large and the longitudinal "perlage" molten pool width is small and the length is long due to the small surface tension of liquid metal and the shear stress of solidification phase boundary coupling (i.e. Marangoni flow). Meanwhile, with the increase of laser power, the thermal energy of the pre-alloyed powder in the forming layer is high enough to fully melt, and the surface tension inside the liquid metal is improved, so that the radial width of the molten channel and the "perlage" molten pool is reasonably expanded, and the longitudinal length of the molten pool decreases gradually and eventually develops from length to width (as shown in Fig. 8(b-c)). However, when the laser power is higher than the appropriate range, the pre-alloyed powder on the forming layer will have higher fluidity due to the excessive absorption of laser energy and cover the adjacent formed layer and the galvanized layer, which result in the width of each molten pool and molten channel are different (as shown in Fig. 8(d)). 

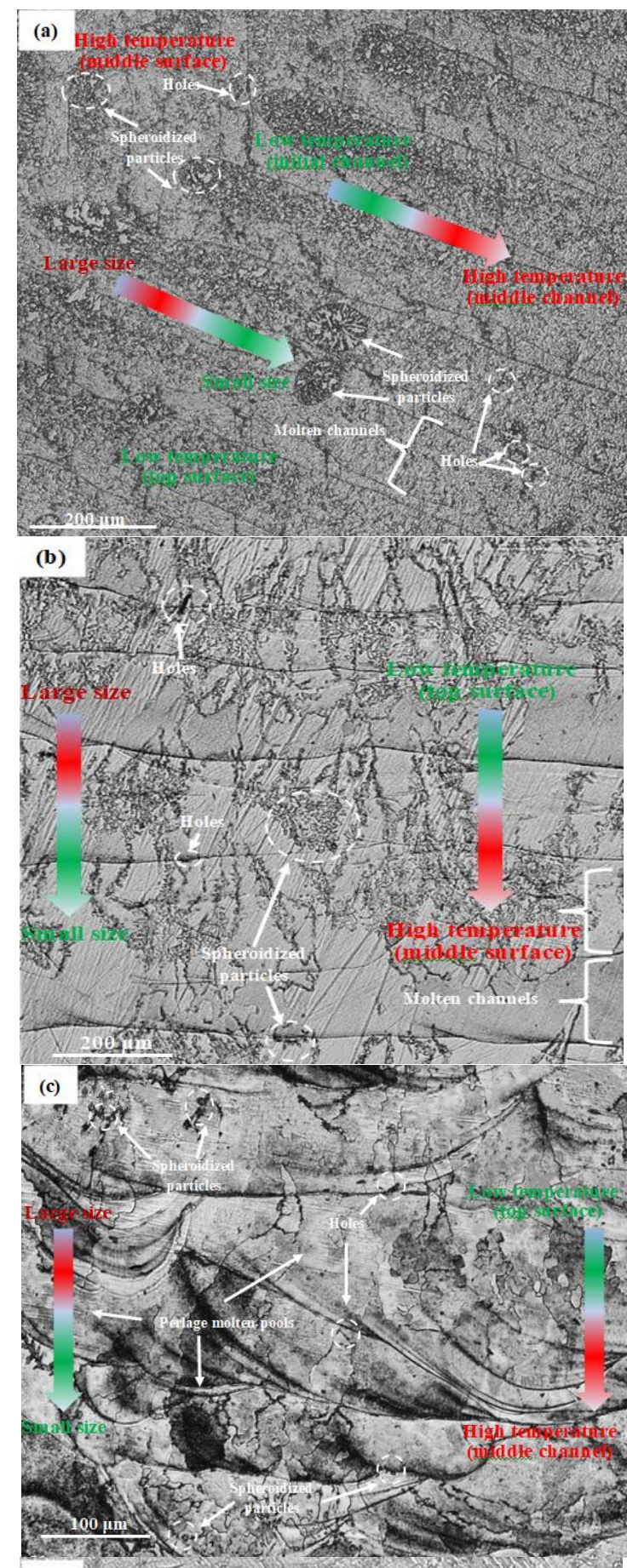

(d)

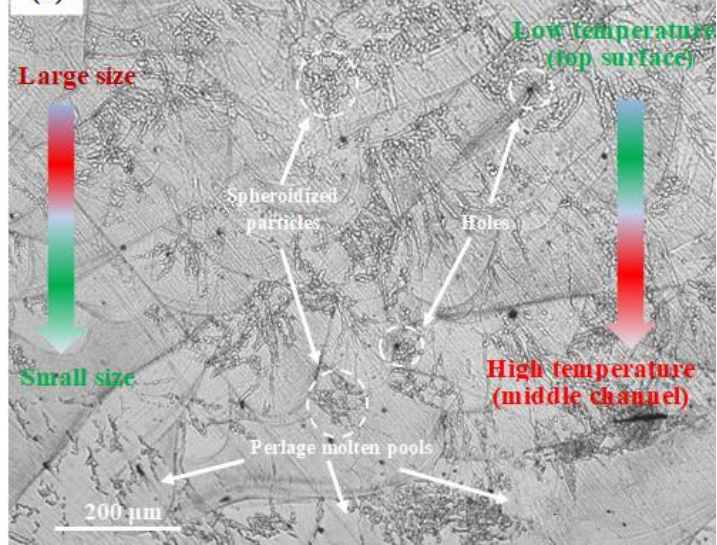

(a) $160 \mathrm{~W}$; (b) $180 \mathrm{~W}$; (c) $200 \mathrm{~W}$; (d) $220 \mathrm{~W}$;

Fig.8 Metallographic phase of samples under different laser power

Subsequently, it can be seen from Fig. 8(a) that when the laser power is low, the pre-alloyed powder absorbs less energy per unit time in the forming area, so most of the pre-alloyed powder in the forming area is not fully melted and a large number of spheroidization and holes are formed in the molten channels and molten pools. Meanwhile, due to the temperature in the forming layer is transferred from the top to the bottom, so the forming layer closer to the middle shows less holes and spheroidization than the top of the forming layer because of more heat energy. For the distribution of holes and spheroidization in the same forming layer (that is, the initial section of the molten channels are higher than that of the middle section of the molten channels), the cause is the same. In addition, the larger size spheroidization and holes are still concentrated at the boundary of the molten pool/molten channel due to the conduction of temperature gradient. Then, the spheroidization and holes decreases with the increase of laser power, and at a laser power of $200 \mathrm{~W}$ to achieve the best (as shown in Fig. 8(b-c)). However, when the laser power is higher than the reasonable range, because the energy obtained by the pre-alloyed powder in the forming aera is too high per unit time, on the one hand, the radial width of the molten pool and the molten channel is increased and through the boundary secondary remelting makes the arrangement of the molten pool and molten channel disorderly; On the other hand, due to the remelting of the formed molten channel and molten pool, the phenomenon of holes and spheroidization in the formed layer increases, and because of the conduction of longitudinal temperature gradient, so there are fewer defects in the middle of the formed layer than in the top / bottom surface (as shown in Fig. 8(d)).

\subsubsection{Scanning spacing}

The scanning spacing refers to the center distance of the laser source between the two adjacent scanning paths, which affects the forming quality and density by acting on the lap rate (the ratio of the lap width of the molten channel to the whole width of the molten channel) between the adjacent molten pool/molten channel. The lap rate (as shown in Fig. 9) of molten pool/ molten channel is generally calculated by formula (4). Based on above forming process parameters range and the best scanning speed parameters and best laser power (scanning speed: $25 \mathrm{~mm} / \mathrm{min}$; laser power: $200 \mathrm{~W}$; scanning spacing: $9-13$ $\mu \mathrm{m})$, the metallographic phase diagram shown in Fig.10 is obtained by dividing the laser power into three stages.

$$
\eta_{l}=\frac{D_{w}}{W} \cdot 100 \%=\frac{W-S}{W} \cdot 100 \%=\left(1-\frac{S}{W}\right) \cdot 100 \%
$$

In which, $D_{\mathrm{w}}$ represents the lap width; $W$ represents the scanning width; $S$ represents the scanning spacing. 


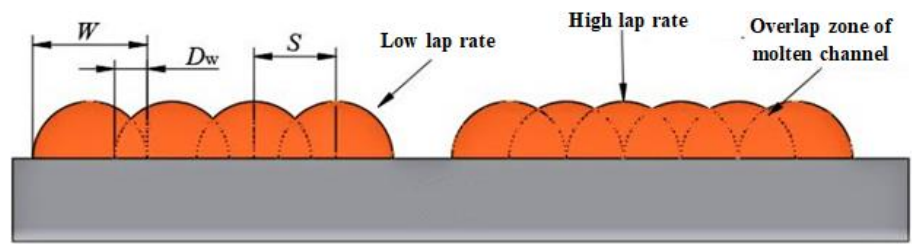

Fig.9 diagrammatic sketch of scanning spacing

It can be seen from Fig. 10 that when the scanning speed and laser power are fixed as medium parameters, and the scanning spacing is higher (as shown in Fig. 10(a)), according to formula (4), the overlap width $\left(D_{\mathrm{w}}\right)$ between adjacent channels is very small, and the pre-alloyed powder at the boundary of molten pool/molten channel will be difficult to form a better metallurgical connection and formed a more obvious depression morphology because of the less heat transfer of adjacent formed parts (as shown in Fig.10(a)). With the decrease of scanning spacing, the lap rate of the molten channel/molten pool increases gradually, which makes the prealloyed powder at the boundary of the molten pool/molten channel receive good heat transfer of the adjacent formed parts and have excellent metallurgical connection characteristics (as shown in Fig.10(b)); When the scanning spacing is reduced to a certain extent, because the lap rate of the molten channel/molten channel is too high, it is easy to remelting the pre-alloyed powder by the high heat transfer of the adjacent molten channel/molten channel under the irradiation of certain intensity laser source parameters, and when it is heated too much, it will expand, and resulting in the surface of the forming layer prone to bulge phenomenon (as shown in Fig.10(c))

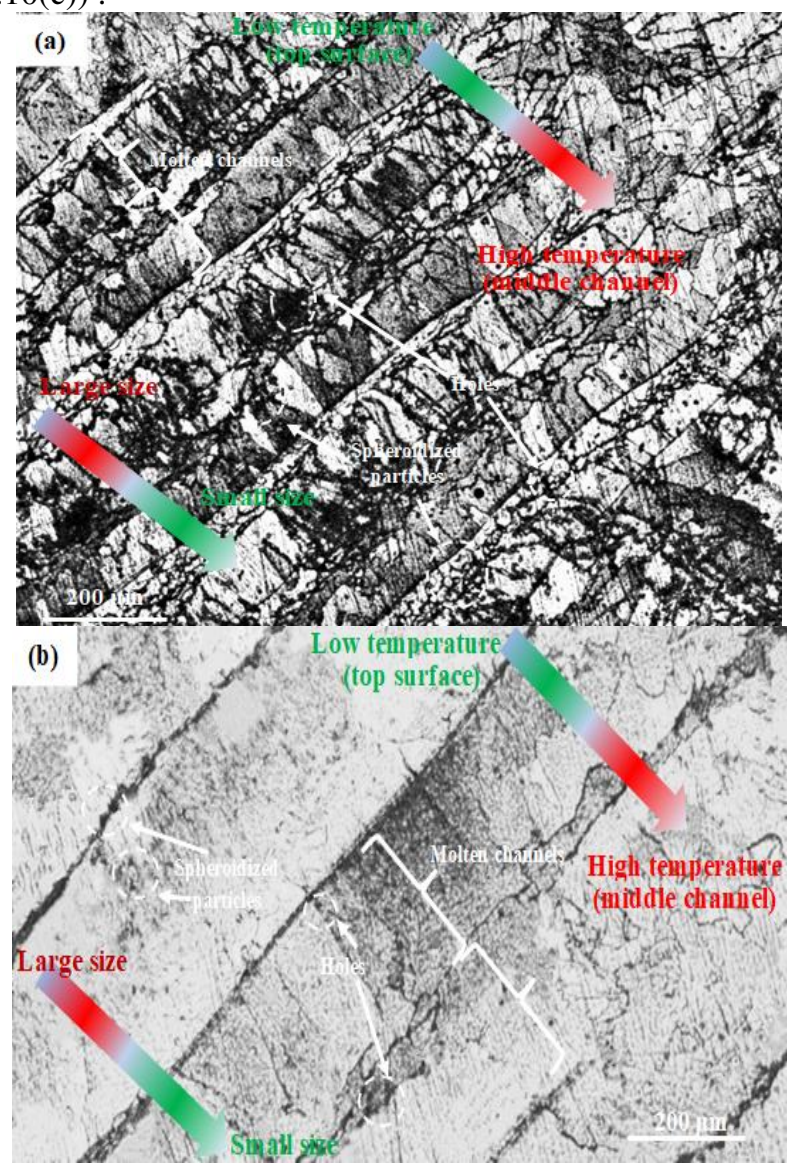

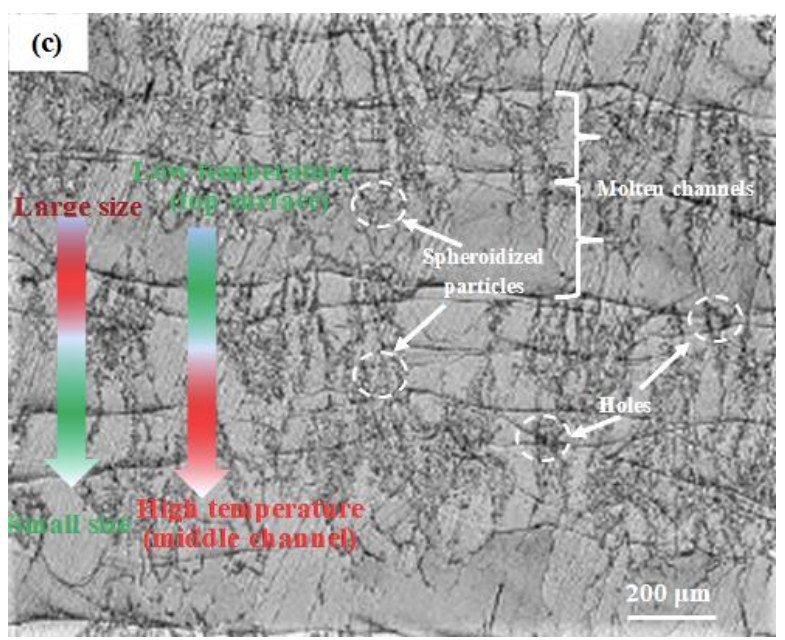

(a) $13 \mu \mathrm{m}$; (b) $11 \mu \mathrm{m}$; (c) $9 \mu \mathrm{m}$;

Fig.10 Metallographic phase of samples under different scanning spacing

Subsequently, it can be seen from Fig. 10(a) that when the scanning spacing is high, the pre-alloyed powder on the molten pool/ molten channel boundary absorbs less energy, so a large number of holes and spheroidization will be produced by obtaining less heat transfer of adjacent formed layers at the boundary of the molten pool/ molten channel. With the decrease of scanning spacing, the overlap width of the molten channel/ molten pool increases due to the decrease of scanning spacing, so that the pre-alloyed powder in the boundary region is properly remelted by sufficient heat. Thus, the above holes and spheroidization are greatly improved (as shown in Fig.10(b)). When the scanning spacing is reduced to a certain extent, the pre-alloyed powder at the boundary of the molten pool / molten channel receives higher heat from the adjacent formed part. Therefore, the boundary part will increase the phenomenon of holes and spheroidization by a higher degree of remelting, and the distribution trend is consistent with the direction of temperature gradient (as shown in Fig.10(c)).

Table 2 Measurement results of samples density under different process parameters

\begin{tabular}{ccccc}
\hline $\begin{array}{c}\text { Scanning } \\
\text { speed } \\
\mathbf{m m} / \mathbf{m i n}\end{array}$ & $\begin{array}{c}\text { Laser } \\
\text { power } \\
/ \mathbf{W}\end{array}$ & $\begin{array}{c}\text { Scanning } \\
\text { spacing } \\
/ \boldsymbol{\mu m}\end{array}$ & Density/\% & $\begin{array}{c}\text { Vickers } \\
\text { hardness/HV }\end{array}$ \\
\hline $\mathbf{4 5}$ & $\mathbf{2 0 0}$ & $\mathbf{1 1}$ & $\mathbf{8 6 . 1}$ & 340 \\
35 & 200 & 11 & 94.9 & 404 \\
$\mathbf{2 5}$ & $\mathbf{2 0 0}$ & $\mathbf{1 1}$ & $\mathbf{9 8 . 4}$ & $\mathbf{4 3 1}$ \\
15 & 200 & 11 & 96.7 & 418 \\
25 & $\mathbf{1 6 0}$ & $\mathbf{1 1}$ & $\mathbf{9 0 . 8}$ & 376 \\
25 & 180 & 11 & 95.3 & 409 \\
$\mathbf{2 5}$ & $\mathbf{2 0 0}$ & $\mathbf{1 1}$ & $\mathbf{9 8 . 9}$ & $\mathbf{4 3 9}$ \\
25 & 220 & 11 & 97.2 & 425 \\
25 & 200 & $\mathbf{1 3}$ & $\mathbf{9 1 . 4}$ & 383 \\
$\mathbf{2 5}$ & $\mathbf{2 0 0}$ & $\mathbf{1 1}$ & $\mathbf{9 9 . 4}$ & $\mathbf{4 4 1}$ \\
25 & 200 & 9 & 96.9 & 423 \\
\hline
\end{tabular}

Finally, the density of the samples under the above process parameters is characterized by Archimedes method, and the measurement results are obtained as shown in Table 2. It can be seen that the relationship between holes and spheroidization 
are proportional to the density of the SLM-formed parts, and the density is proportional to the hardness of the material, in which the density and hardness reaches the highest $(99.4 \%$, $441 \mathrm{HV}$ ) when the laser power is $220 \mathrm{w}$, the scanning speed is $25 \mathrm{~mm} / \mathrm{min}$ and scanning spacing is $11 \mu \mathrm{m}$.

\subsection{Analysis of optimal process parameters of 17-4PH SLM-formed parts}

In the previous study of the influence of several different main parameters on the microstructure, density and hardness of the formed parts, the local optimal process parameters were obtained. In this experiment, we mainly studied the mechanical properties of the molded parts under different parameter array under normal temperature and static load tensile test by orthogonal test. In order to obtain the global optimal forming process parameters, the adjustable range of the parameters of the forming equipment is divided into three levels: high, low and high (as shown in Table 3), [16] and the tensile properties of each sample are evaluated by orthogonal test.

It can be seen from the orthogonal test results that the samples 1\#, 5\#, 9\# all have high tensile properties. Furthermore, the elongation of these three groups of parameters were compared and found that when the laser power is $200 \mathrm{~W}$, scanning speed is $25 \mathrm{~mm} / \mathrm{min}$ and the scanning spacing is $11 \mu \mathrm{m}$ have the highest mechanical properties (that is, the yield strength is $1132 \mathrm{MPa}$, the tensile strength is $1323 \mathrm{MPa}$, the elongation is $16.6 \%$ ). Therefore, it can be seen that the mechanical behaviour of the 17-4 PH alloy sintered by selective laser melted are much higher than that of the ASTM A564 criteria $\left(\sigma_{\mathrm{s}}>1000 \mathrm{MPa}, \sigma_{\mathrm{B}}>1000 \mathrm{MPa}, \delta>12 \%\right)$.

Table 3 Orthogonal test results

\begin{tabular}{|c|c|c|c|c|c|c|}
\hline \multirow[b]{2}{*}{$\begin{array}{c}\text { Group } \\
\text { Number }\end{array}$} & \multicolumn{3}{|c|}{ Impact factors } & \multicolumn{3}{|c|}{ Mechanical properties } \\
\hline & $\begin{array}{c}\text { Laser } \\
\text { power } \\
\text { /W }\end{array}$ & $\begin{array}{l}\text { Scannin- } \\
\text { g speed } \\
\mathrm{mm} / \mathrm{min}\end{array}$ & $\begin{array}{c}\text { Scanning } \\
\text { spacing } \\
/ \mu \mathrm{m}\end{array}$ & $\sigma_{s} /$ Mpa & $\sigma_{B} / \mathbf{M p a}$ & $\delta / \mathbf{M p a}$ \\
\hline 1 & 180 & 15 & 9 & 1127 & 1317 & 16.3 \\
\hline 2 & 180 & 25 & 11 & 1089 & 1169 & 15.6 \\
\hline 3 & 180 & 35 & 13 & 1027 & 1089 & 14.7 \\
\hline 4 & 200 & 15 & 9 & 1107 & 1217 & 11 \\
\hline 5 & 200 & 25 & 11 & 1132 & 1323 & 16.6 \\
\hline 6 & 200 & 35 & 13 & 1043 & 1198 & 15.9 \\
\hline 7 & 220 & 15 & 9 & 1076 & 1288 & 15.8 \\
\hline 8 & 220 & 25 & 11 & 1108 & 1305 & 14.9 \\
\hline 9 & 220 & 35 & 13 & 1115 & 1321 & 16.1 \\
\hline
\end{tabular}

\section{Conclusions}

Due to the principle of selective laser melting is to melt the pre-alloyed powder by high energy laser beam, and the rapid cooling solidification occurs after the laser beam is removed. Therefore, the forming density and quality of the material are mainly restricted by the laser energy of the laser source of the equipment in each formed position and caused by the longitudinal/transverse heat transfer during the sequential sintering between adjacent molten pools/ molten channels. In this paper, the control variable method and orthogonal test method are used to study and analyze the related process parameters, and it is found that:

1) The laser scanning speed, laser power and scanning spacing are all changed by changing the absorption heat state of the pre-alloyed powder in the scanning path to change the solid-solution aging process of the material so as to affect the forming density and forming quality. Furthermore, the laser scanning speed mainly by changing the sintering time in the unit forming area to change the thermal energy of the prealloyed powder, the laser power directly determines the heat energy of the unit forming area of the pre-alloyed powder in unit time, and the scanning spacing mainly determines the absorption heat energy of the pre-alloyed powder at the boundary of the molten pool / molten channel.

2) Because the pre-alloyed powder has different thermal energy under different process parameters, it is easy to form the spheroidized particles with small ellipsoidal structure and irregular holes with large size at the boundary position of the molten channels/ molten pools under the longitudinal/ransverse multidimensional heat conduction between adjacent molten channels / molten pools, and the distribution mode (size from large to small and quantity from large to small) is consistent with the direction of temperature gradient.

3) The density of the $17-4 \mathrm{PH}$ stainless steel alloy is proportional to the size and quantity of the holes and spheroidization in the formed layer, while the density of the material is related to the macroscopic hardness and tensile properties. And the mechanical behaviour of selective laser melted 17-4 PH alloy (the yield strength is $1132 \mathrm{MPa}$, the tensile strength is $1323 \mathrm{MPa}$, the elongation is $16.6 \%$ ) is higher than ASMT A 564 standard by using the optimal parameters obtained by orthogonal test.

Acknowledgments This research is funded by National Natural Science Foundation of China (NSFC) under grant number 51705392, the project of 2019 Yulin Science and Technology Program under grant number K20190176.

Authors' contributions conceptualization, Liang Huang and Yan Cao; methodology, Gaohong Li; validation, Liang Huang, Yuanfei Wang and Yunpeng Dang; formal analysis, Liang Huang and Yao Li; investigation, Yunpeng Dang; resources, Yuanfei Wang; writing-original draft preparation, Liang Huang and Yan Cao; writing-review and editing, Liang Huang; project administration, Yan Cao and Yuanfei Wang; funding acquisition, Yan Cao and Liang Huang”.

Funding This research is funded by National Natural Science Foundation of China (NSFC) under grant number 51705392, the project of 2019 Yulin Science and Technology Program under grant number K20190176.

Data availability All data included in this study are available upon request by contact with the corresponding author. 


\section{References}

1. Brighenti R, Cosma MP, Marsavina L (2021) Laser-based Additively Manufactured Polymers: A Review on Processes and Mechanical Models. J Mater Sci 56:961-998.

https://doi.org/10.1007/s10853-020-05254-6

2. Razavykia A, Brusa E, Delprete C (2020) An Overview of Additive Manufacturing Technologies-A Review to Technical Synthesis in Numerical Study of Selective Laser Melting. Materials 13:93-96. https://doi.org/10.3390/ma13173895

3. Stolt R, Elgh F (2020) Introducing Design for Selective Laser Melting in Aerospace Industry J Computdes Eng 7:489-497. https://doi.org/10.1093/jcde/qwaa042

4. Zhang L, Song B, Fu JJ (2020) Topology-optimized Lattice Structures with Simultaneously High Stiffness and Light Weight Fabricated by Selective Laser Melting: Design, Manufacturing and Characterization. J Manuf Process 56:1166-1177. https://doi.org/10.1016/j.jmapro.2020.06.005

5. Yu ZY, Zheng Y, Chen JM (2020) Effect of Laser Remelting Processing on Microstructure and Mechanical Properties of 17-4 PH Stainless Steel during Laser Direct Metal Deposition. J Mater Process Tech 284:1-13. https://doi.org/10.1016/j.jmatprotec.2020.116738

6. Spierings AB, Schoepf M, Kiesel R (2013) Optimization of SLM productivity by aligning $17-4 \mathrm{PH}$ material propertieson part requirements. Rapid Prototyping J 20:444-448. https://doi.org/10.1108/rpj-04-2013-0045

7. Gu H, Gong H, Pa D(2016) Influences of energy density on porosity and microstructure of selective laser melted17-4PH stainless steel. Proceedings of Annual International Solid Freeform Fabrication Symposium-An AdditiveManufacturing Conference 25: 411-417. https://doi.org/10.1016/j.jmapro.2016.12.008

8. Harish I, John SDJ, Somayeh P (2018) Effects of particle characteristics on the microstructure and mechanical properties of 17-4 PH stainless steel fabricated by laser-powder bed fusion. Mater Res Technol 331:192-203. https://doi.org/10.1016/j.powtec.2018.03.025

9. Dai SM, Xu ZM, Hu Z.H (2019) Study on Dimensional Relative Density Precision and Surface Roughness Stainless Steel SLM Forming 17-4PH. Optics and Optoelectronics 17:17-23. https://doi.org/10.19519/j.cnki.1672-3392.2019.02.003

10. Gu XL, Shi JG, Liu P (2017) Study on Formation of Selective Laser Melting 17-4 PH Alloy. Mech Eng 69-71. https://doi.org/10.19519/j.cnki.1002-2333.2017.02.0069.03

11. Gill SS, Kaplas M (2011) Efficacy of powder-based three-dimensional printing (3DP) technologies for rapid casting of light alloys. Int $\mathbf{J}$ Adv Manuf Tech 52:53-64. https://doi.org/10.1007/s00170-010-2716-1

12. Sayanjali M, Rezadoust AM, Sourk FA (2020) Tailoring PhysicoMechanical Properties and Rheological Behavior of ABS Filaments for FDM Via Blending with SEBS TPE. Rapid Prototyping J 1-5. https://doi.org/10.1108/RPJ-06-2019-0173

13. Lee HJ, Dao VH, Ma YW (2020) Effects of Process Parameters on the High Temperature Strength of 17-4PH Stainless Steel Produced by Selective Laser Melting. J Mech Sci Technol 34:3261-3272. https://doi.org/10.1007/s12206-020-0718-y

14. Huang RK, Dai N, Cheng XS (2020) Topology Optimization of Lattice Support Structures for Heat Conduction in Selective Laser Melting. Int J Adv Manuf Tech 109:1841-1851. https://doi.org/10.1007/s00170-020-05741-9

15. Xiao R, Yang W, Kai C (2007) Porosity Characterization in Laser Welds of Al-Li alloy 1420. Applied Laser, 27:13-17. https://doi.org/10.3969/j.issn.1000-372X.2007.01.004

16. Wan L, Xia ZX, Song YA (2020) Parameter Optimiazation of Selective Laser Melting Fabricated Titanium Alloy using Skin-Core and Triple Contour Scanning Strategy. Journal of Laser Applocations 32:15-20. https://doi.org/10.2351/7.0000180 
Figures

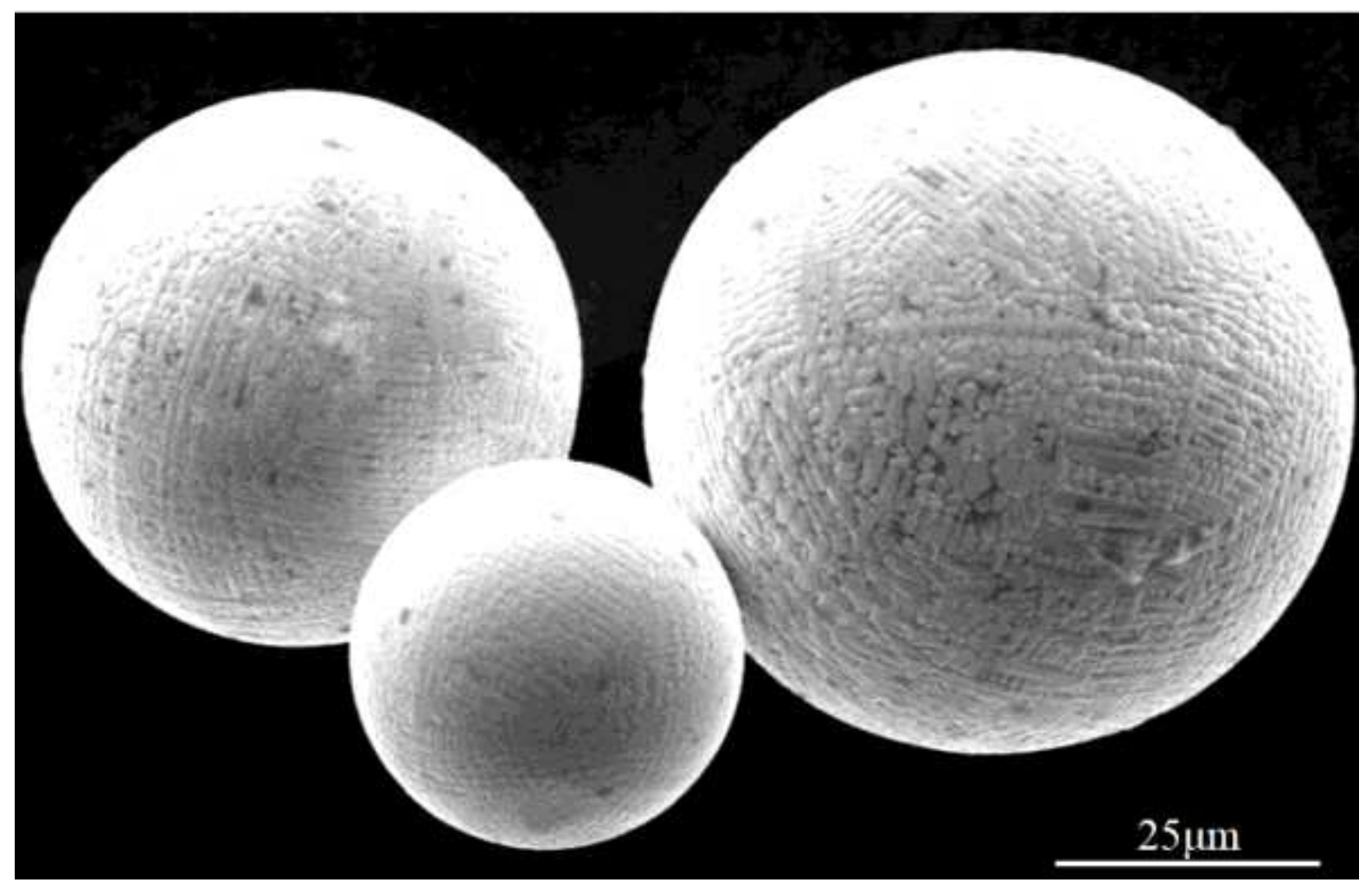

Figure 1

The microstructure of 17-4PH pre-alloy powder

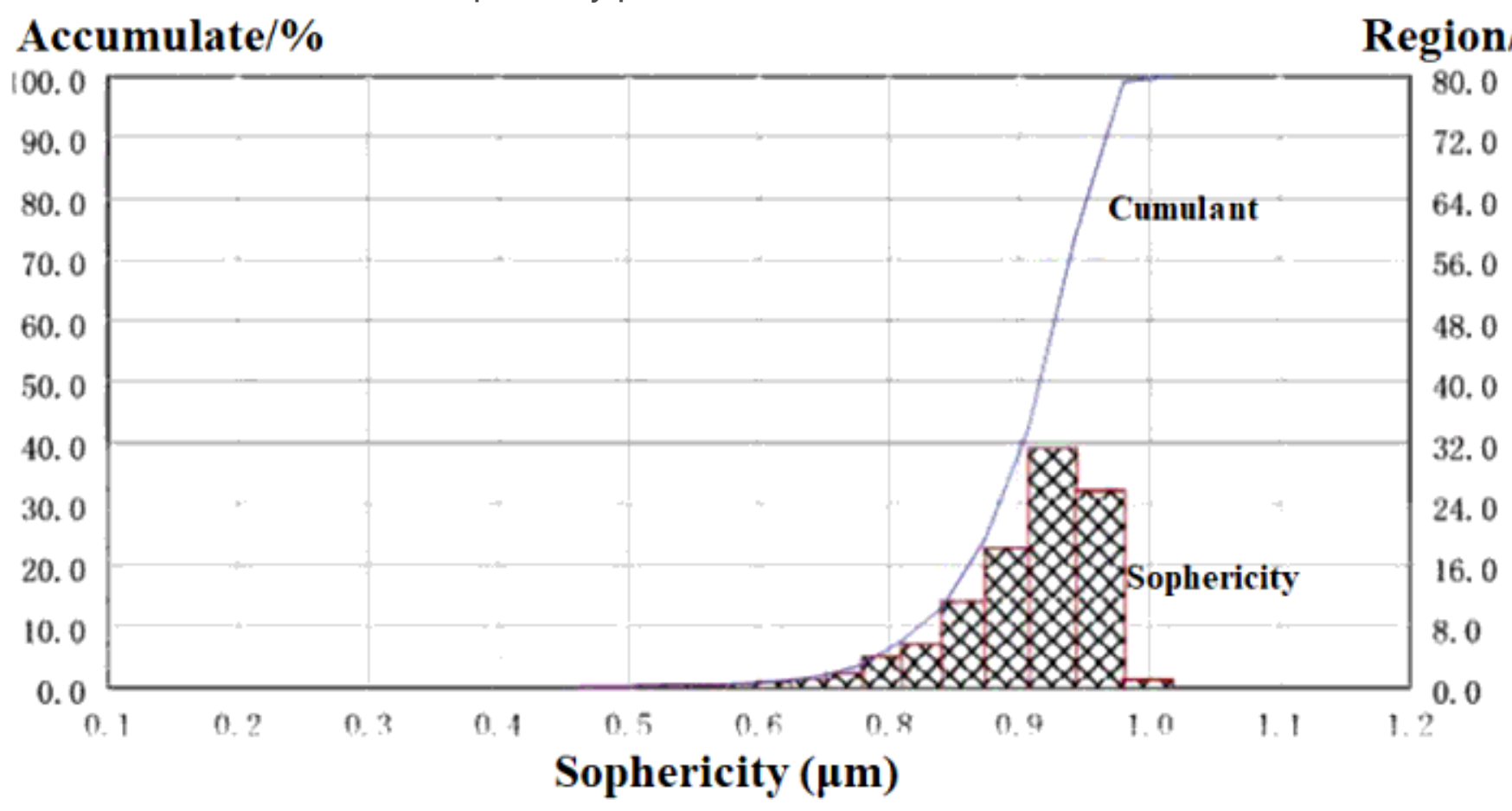

Figure 2

The sophericity distribution of $17-4 \mathrm{PH}$ pre-alloy powder 


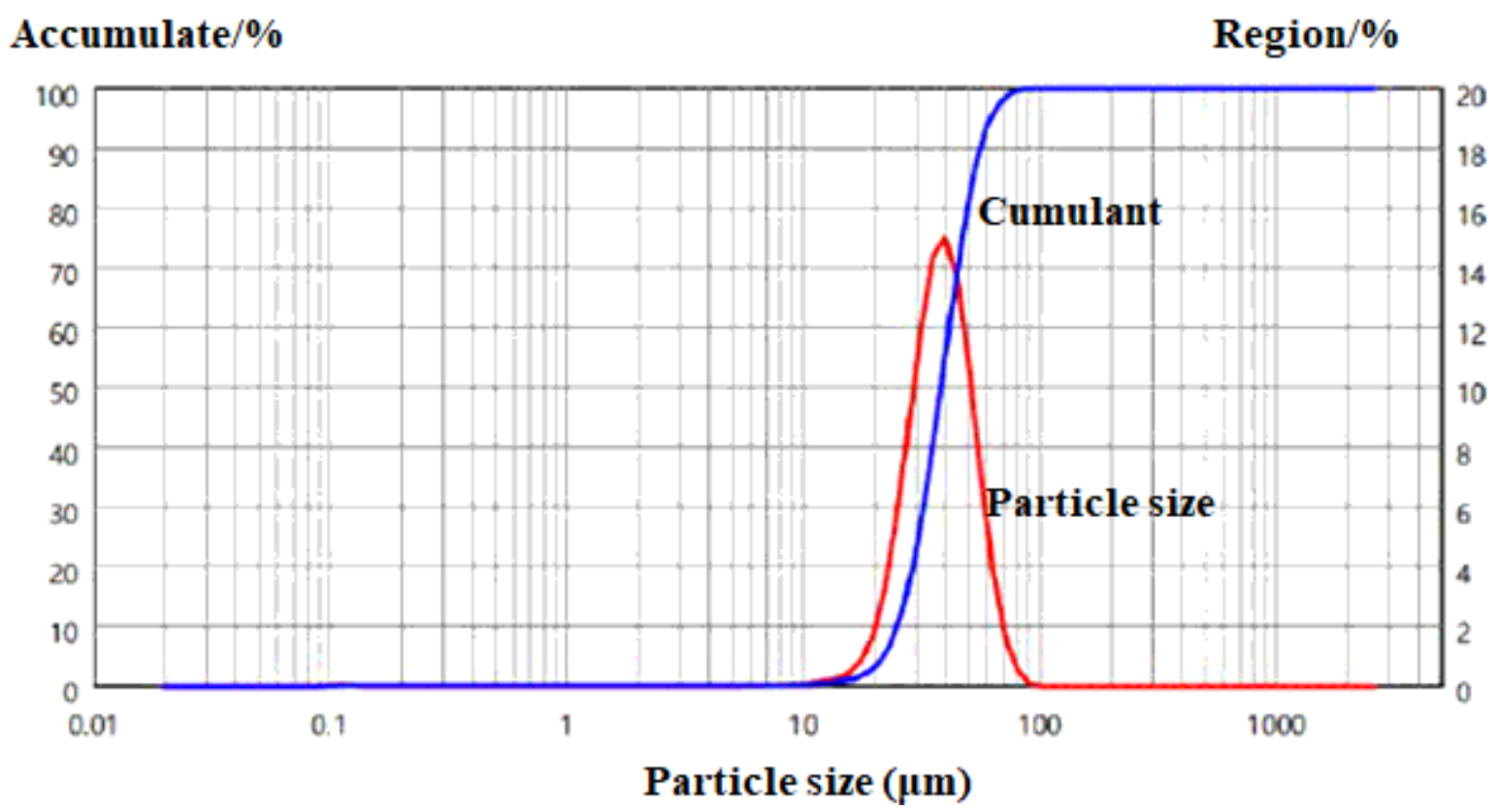

Figure 3

The particle size distribution curve of $17-4 \mathrm{PH}$ pre-alloy powder

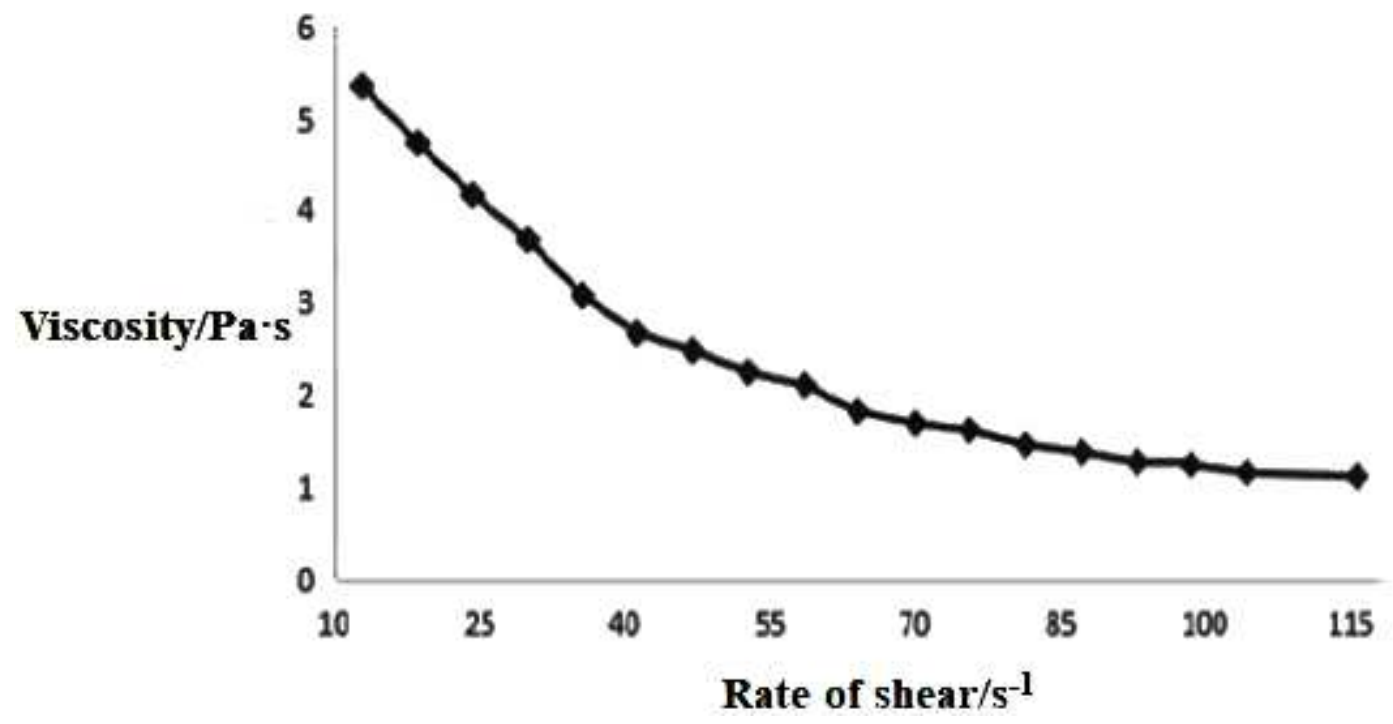

Figure 4

Viscosity curve with shear rate 


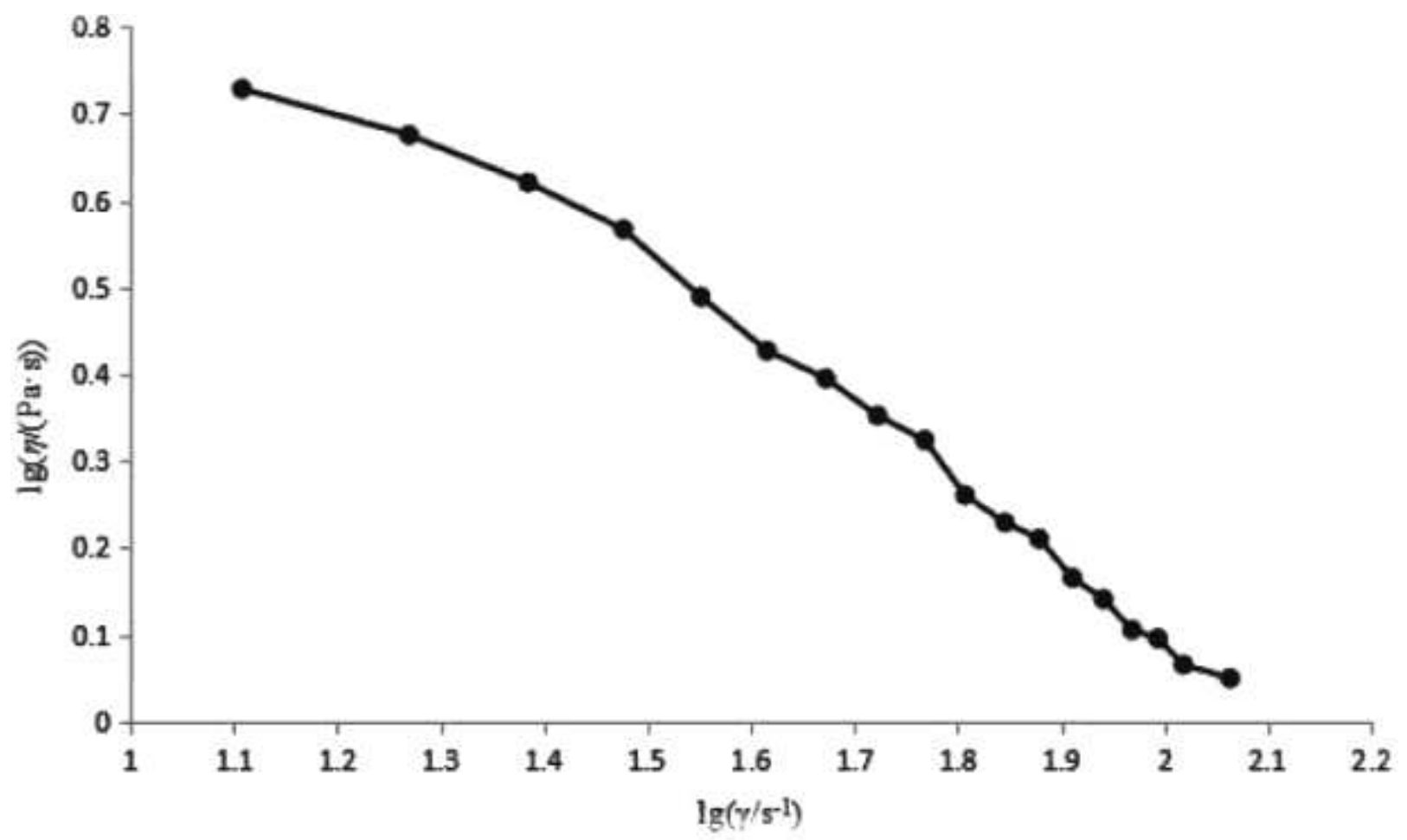

Figure 5

Ign-Igy relation curve

Unit: mm
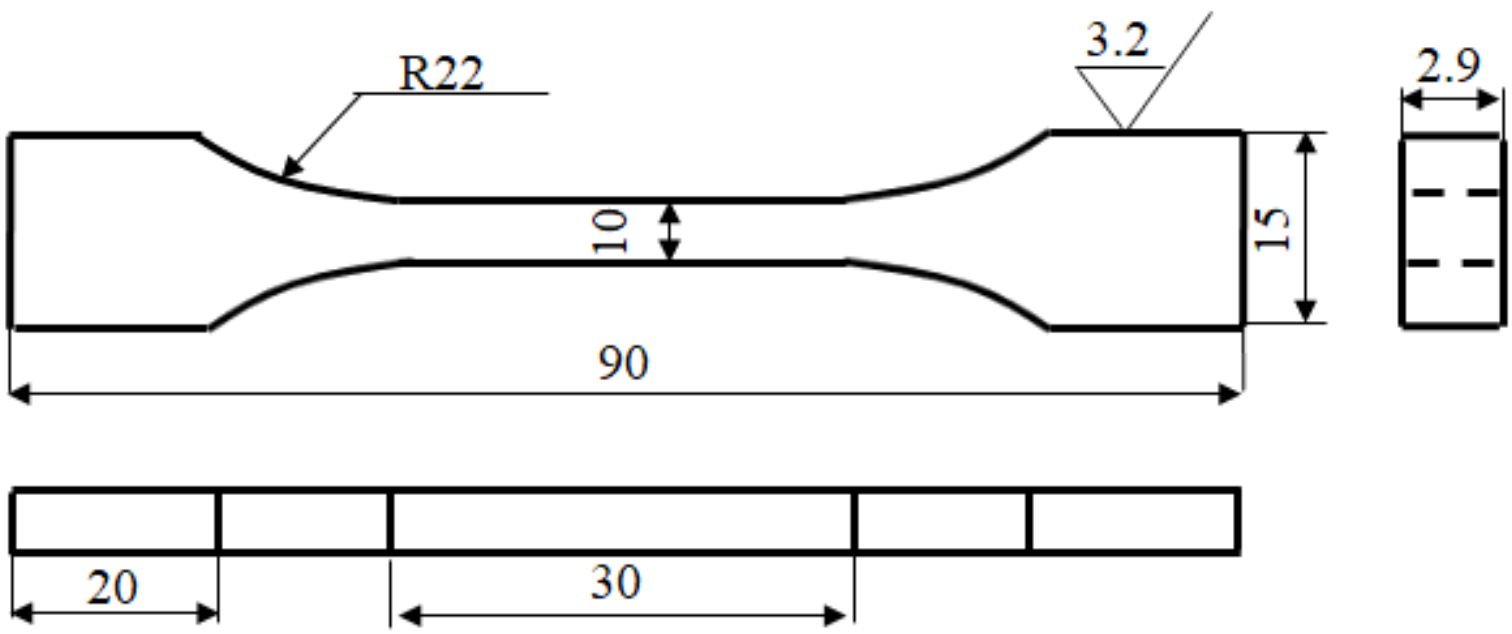

Figure 6

Schematic diagram of the tensile samples 

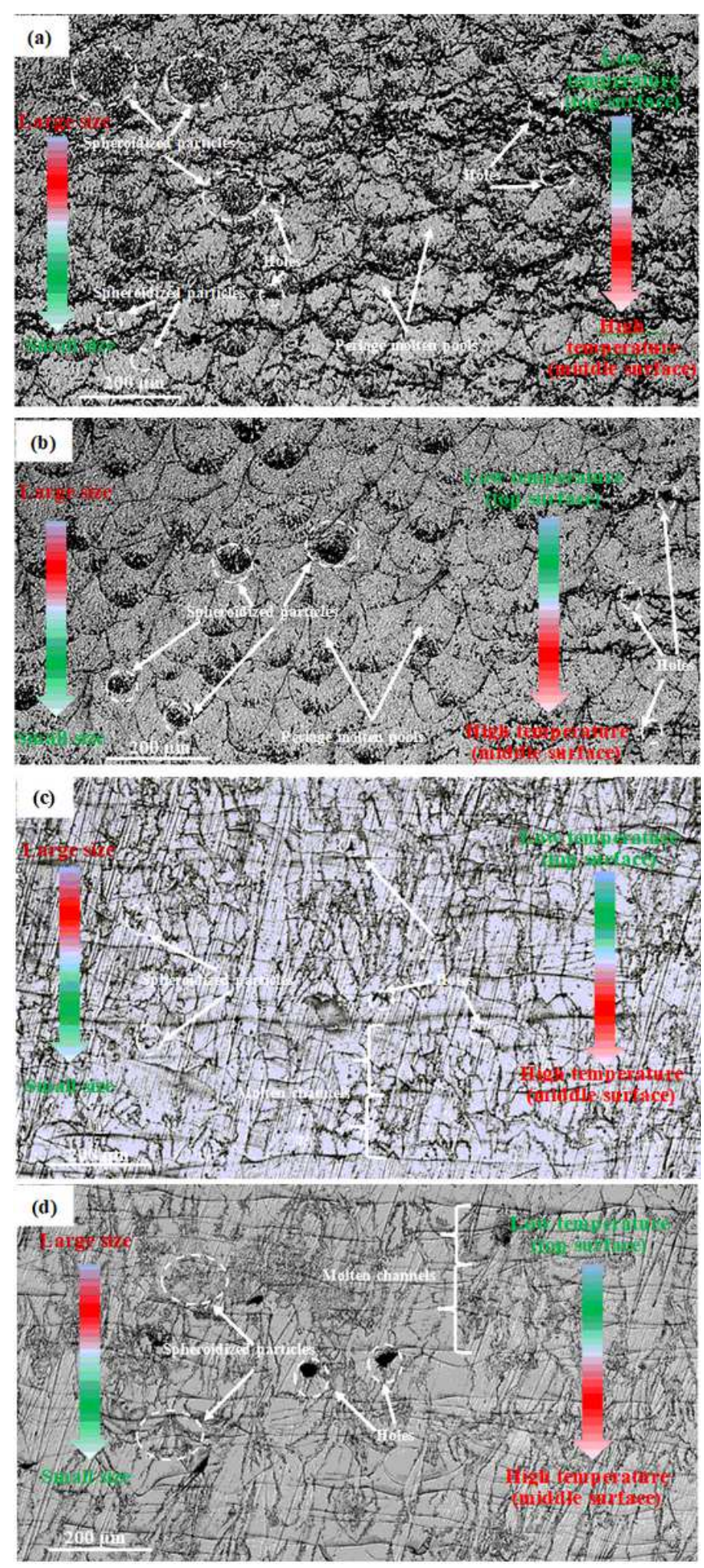

\section{Figure 7}

(a) $45 \mathrm{~mm} / \mathrm{min}$; (b) $35 \mathrm{~mm} / \mathrm{min}$; (c) $25 \mathrm{~mm} / \mathrm{min}$; (d) $15 \mathrm{~mm} / \mathrm{min}$; Metallographic phase of samples under different scanning speed 

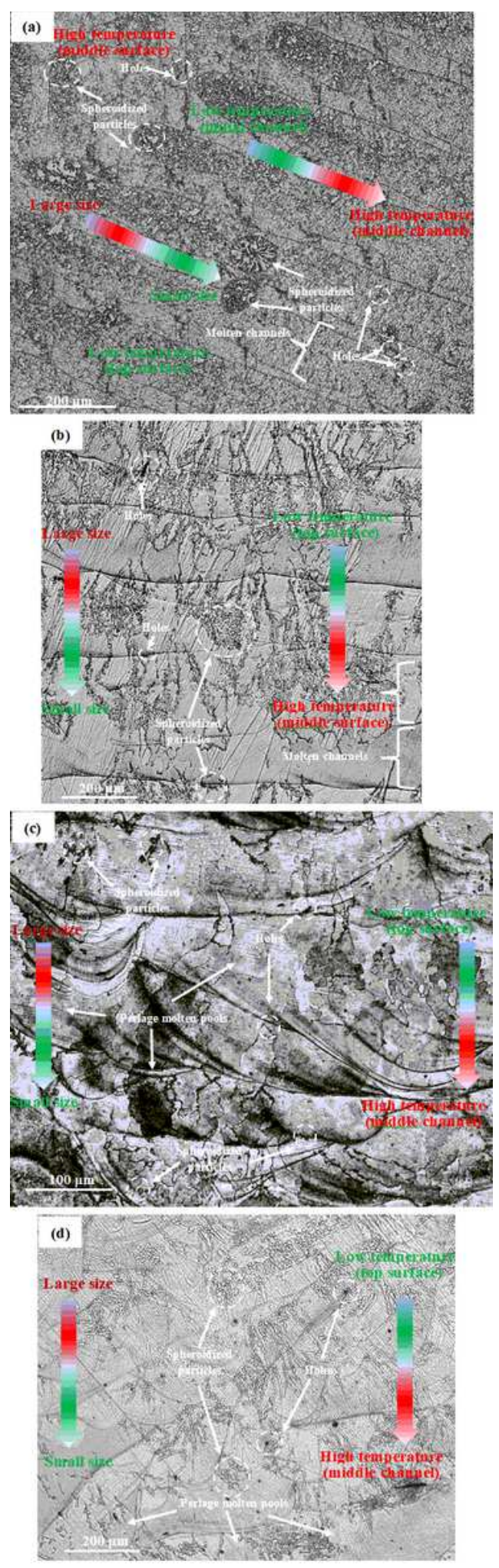

Figure 8

(a) 160W; (b) 180W; (c) 200W; (d) 220W; Metallographic phase of samples under different laser power 


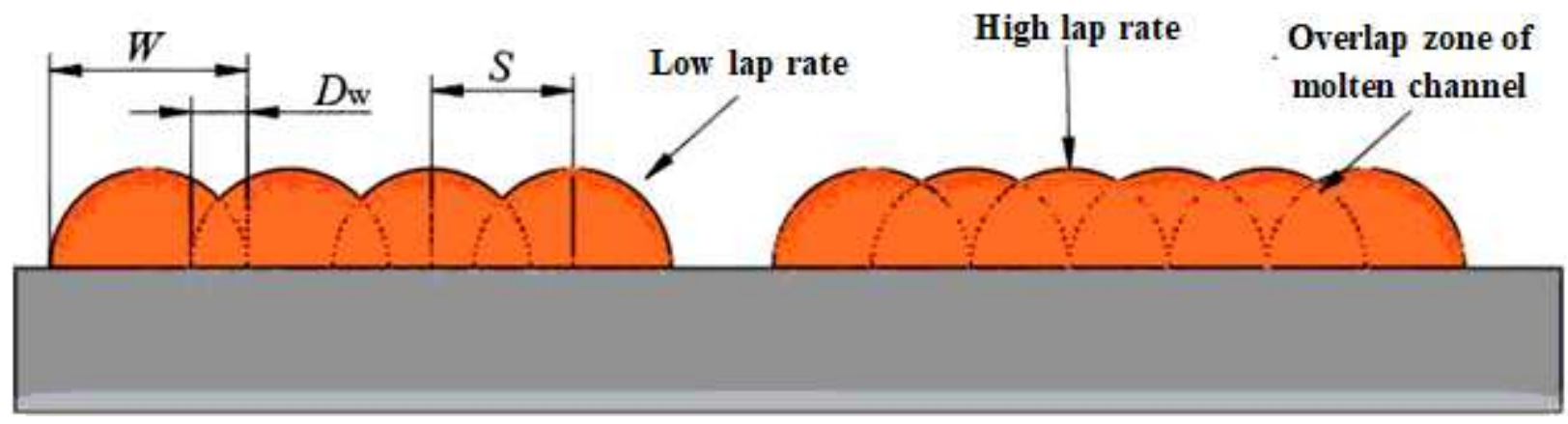

Figure 9

diagrammatic sketch of scanning spacing 

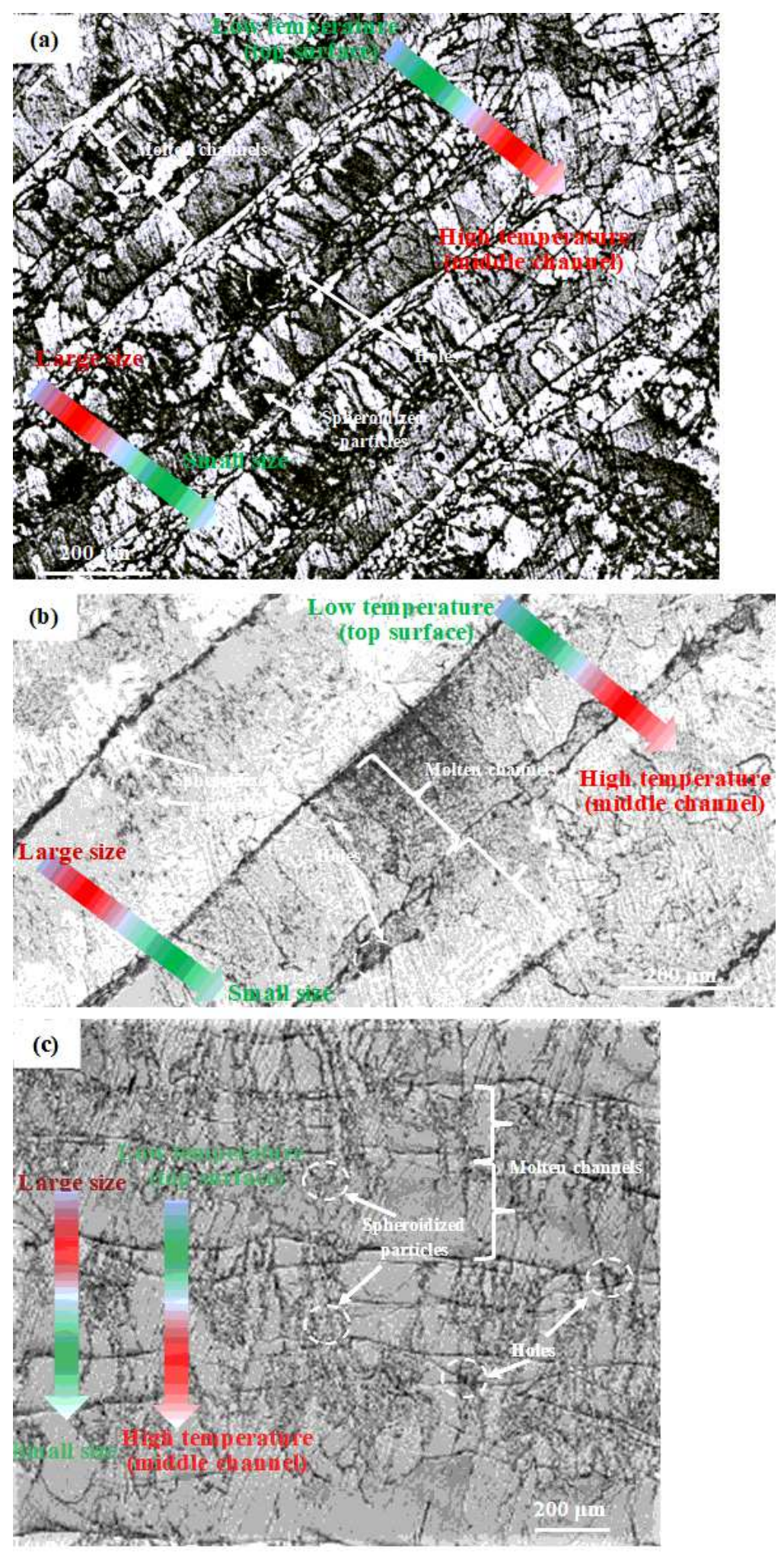

Figure 10

(a) $13 \mu \mathrm{m}$; (b) $11 \mu \mathrm{m}$; (c) $9 \mu \mathrm{m}$; Metallographic phase of samples under different scanning spacing 